\title{
Pseudoaneurysm: a rare complication of distal transradial access in the anatomical snuffbox
}

\author{
Maryam Boumezrag ${ }^{1}$, Bianca Ummat ${ }^{2}$, Jonathan Reiner ${ }^{2}$, Anthony Venbrux ${ }^{1}$ and Shawn Sarin ${ }^{1 *}$ (D)
}

\begin{abstract}
Background: This report presents a case of distal radial artery pseudoaneurysm following cardiac catheterization and its successful endovascular management. Due to its novelty as a catheterization site, few to no reports exist regarding the complications associated with distal radial access.

Case presentation: A patient presented to the emergency department with severe wrist and hand swelling $48 \mathrm{~h}$ after successful cardiac catheterization via distal radial artery access. Angiography revealed a pseudoaneurysm which was embolized with Onyx ${ }^{\mathrm{TM}}$. Post intervention angiogram showed exclusion of the pseudoaneurysm and preservation of the left palmar arch vasculature.

Conclusion: The case presented herein demonstrates a rare complication of distal radial access at the anatomical snuffbox.
\end{abstract}

\section{Background}

Transradial access has gained popularity over the femoral approach as the access site of choice, especially for percutaneous coronary interventions (PCI). The RIVAL study showed that compared to femoral access, radial access has significantly less risk of hematoma and pseudoaneurysm formation (Jolly et al. 2019). Despite these advantages, the transradial approach has drawbacks including radial artery occlusion (RAO) and nonocclusive radial inury (Sinha et al. 2017)Body habitus and shoulder mobility can also limit utilization of left radial access (Davies and Gilchrist 2018). A more recent method involving access at the anatomical snuffbox has been developed for cases in which more distal access is desired. This technique, referred to as left distal transradial angiography (ldTRA), accesses the artery at the anatomical snuffbox and can be used as an appropriate alternative to right or left radial angiography and interventions (Kiemeneij 2017). Due to its novelty as a catheterization site, only few reports exist regarding the complications associated with distal radial access at the anatomical

\footnotetext{
* Correspondence: ssarin@mfa.gwu.edu

${ }^{1}$ Department of Radiology, George Washington University, 900 23rd St NW, Washington, DC 20037, USA

Full list of author information is available at the end of the article
}

snuffbox. We describe a novel technique for treatment of RAP using Onyx ${ }^{\text {tx }}$ as the primary embolic agent. To our knowledge, there are no reports concerning embolization of iatrogenic radial artery pseudoaneurysm with Onyx ${ }^{\mathrm{m}}$.

\section{Case presentation}

A patient presented for planned elective cardiac catheterization as part of standard pre-Transcatheter Aortic Valve Replacement (TAVR) workup. His past medical history was significant for CAD status post CABG and mechanical mitral valve, CVA while subtherapeutic on anticoagulation, and severe aortic stenosis. He was anticoagulated for his mechanical mitral valve and was instructed to hold Coumadin 3 days prior to the procedure. The procedure was performed via the distal left radial with a 6F JL4 catheter. Cardiac catheterization was uneventful. Due to risk of CVA risk with a mechanical valve, the patient was discharged later in the day with instructions to take Coumadin $10 \mathrm{mg}$ the night of the procedure and resume Lovenox and Coumadin the following day. However, he noted progressive wrist and hand swelling over the next $48 \mathrm{~h}$ and was instructed to come to the emergency department. 
In the ED, physical exam showed massive swelling of the left digits and the dorsal and palmar left hand, and minor swelling of the left wrist. Significant ecchymosis was noted on both surfaces of the hand. Sensation to light touch was intact. Movement was limited due to swelling and pain. Pulse oximetry in all 5 digits was $>95 \%$. The vascular and plastic surgery services were consulted. It was not felt that fasciotomy or surgical repair was required urgently. However, despite holding manual pressure on the hand, continued hematoma formation occurred.

The patient was brought to IR for evaluation. Access was obtained via right femoral artery. Catheter and wire were advanced under fluoroscopic guidance into the left upper extremity. There was difficulty advancing the wire and catheter combination into the left upper arm due to significant atherosclerotic disease, especially in the right common iliac artery. A multistation angiogram of the left upper extremity was performed. This showed a pseudoaneurysm off the distal aspect of the left radial artery. Advancement of a microcatheter was attempted from the right femoral access, however, was unable to advance the microcatheter beyond the level of the elbow due to significant vessel tortuosity. Therefore, it was decided to reaccess the arterial system more proximal to the area of vessel injury. Using ultrasound guidance and a micropuncture set, the proximal aspect of the left radial artery was accessed in an antegrade fashion. Through the micro puncture sheath, a microcatheter was advanced into the radial artery and a selective left radial angiography performed. This confirmed presence of a pseudoaneurysm off the distal aspect of the radial artery at the level of the base of the first metacarpal (Fig. 1). The microcatheter was advanced to the level of the injury and into the pseudoaneurysm itself. Embolization material, Ethylene-Vinyl Alcohol Copolymer liquid embolic (Onyx ${ }^{\mathrm{Tm}} 18$, Medtronic, Irvine, CA), (2 cc) was administered from the catheter after first flushing the catheter with DMSO. Post intervention angiogram showed exclusion of the pseudoaneurysm and preservation of the left palmar arch vasculature (Fig. 2). Hemostasis in the right femoral access was obtained using an Angio-Seal. Hemostasis in the left radial access was obtained using a radial compression band.

Immediately following this procedure, the hand was noted to be increasingly tense and swollen with worsening skin blistering and weeping, likely related to the hand not being elevated as well as injection of contrast in to the area. The hand movement was significantly more restricted due to the swelling and pain. Sensation was intact. Patient continued to deny paresthesia. Thumb pulse ox was $95 \%$. Radial pulse $2+$ right femoral pulse $2+$. The patient was monitored in the intensive care unit (ICU) for frequent neuro vascular checks. Overnight, there was improvement in the pain and swelling, which over the next day improved with elevation. The patient

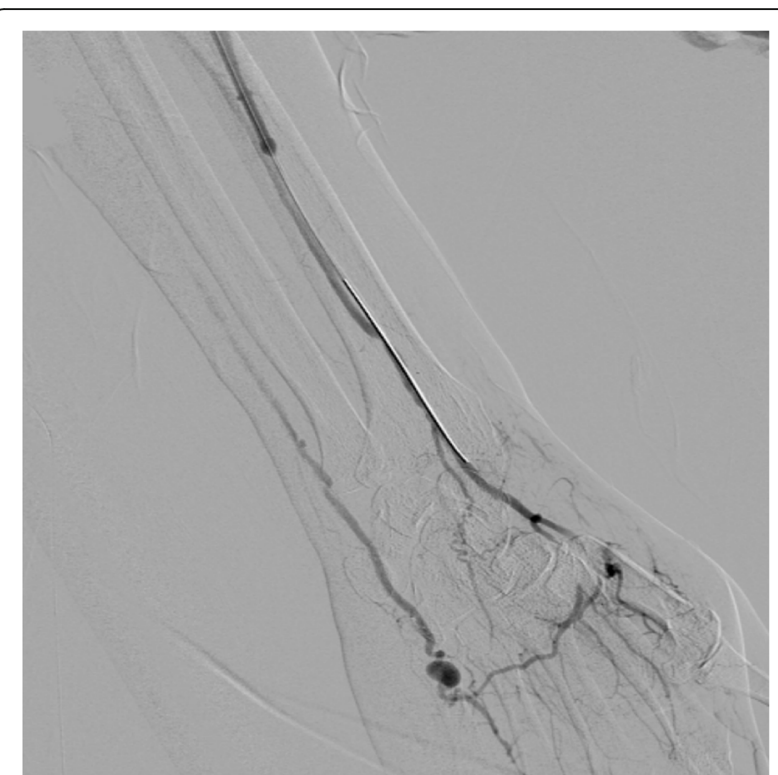

Fig. 1 Pre-embolization angiogram showing a pseudoaneurysm in the distal aspect of the radial artery at the level of the base of the first metacarpal

recovered uneventfully with no ischemic complications. Two weeks following the radial artery pseudoaneurysm repair, the patient was seen in clinic by cardiothoracic surgery for continued management of his aortic stenosis. At the time of visit, he complained of right groin pain concerning for pseudoaneurysm. An ultrasound was obtained the following day and showed a $4.7 \times 4.2 \times 2.4 \mathrm{~cm}$ hematoma but no signs of pseudoaneurysm. He was hemodynamically stable at this time and conservative management was

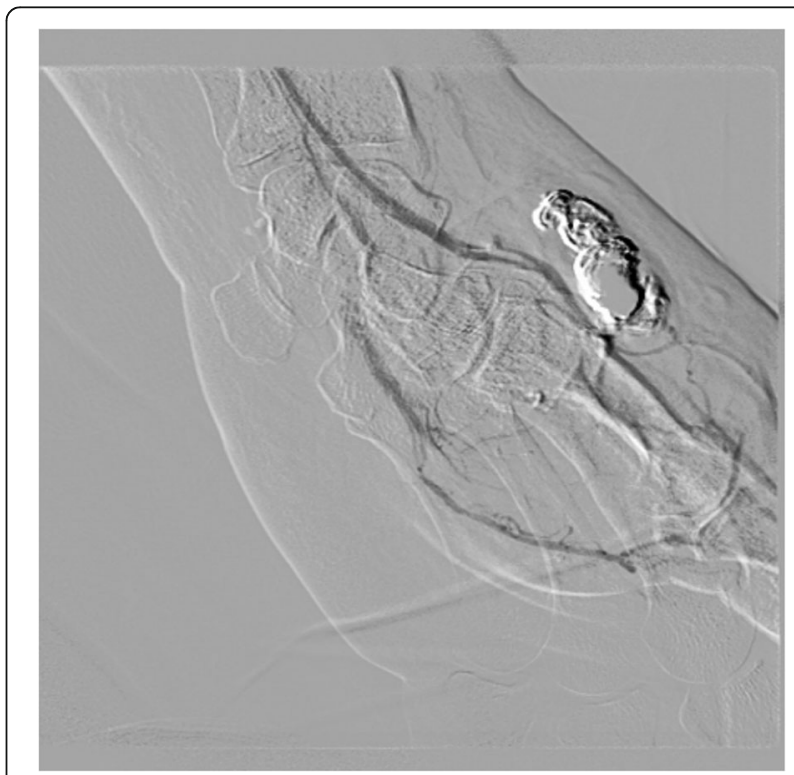

Fig. 2 Post intervention angiogram showing exclusion of the pseudoaneurysm and preservation of the left palmar arch vasculature 
deemed appropriate. The patient was seen again in clinic the following day and reported an improvement in his pain over $24 \mathrm{~h}$. At 6 month follow-up, the patient remained asymptomatic.

\section{Discussion}

Pseudoaneurysms are a well-known iatrogenic complication of arterial catheterization (Esposito et al. 2006). The pathogenesis originates from inadequate thrombus formation after the catheter or sheath is removed, thus causing a hematoma between the tunica media and tunica adventitia which communicates with the arterial lumen. It is estimated that pseudoaneurysms occur in $.2 \%$ to $3 \%$ of femoral artery catheterizations (Stone et al. 2014). The incidence is much more rare for radial artery catheterization and is estimated at $0.009 \%$ (Tatli et al. 2015). The prevalence of radial artery pseudoaneurysm (RAP) is likely to increase in the future as radial access continues to grow in popularity.

The diagnosis of RAP is usually based on a high degree of clinical suspicion and often followed by a doppler ultrasound. Several other imaging modalities can also be used, though angiography remains the gold standard for diagnosis (Mohan et al. 2017).

The potential risks associated with RAP can be significant due to the artery's proximity to the palmar arch as well as its superficial location within a highly mobile region of the wrist. These risks include distal thromboembolism, digital ischemia, hemarthrosis, parasthesias, rupture, skin ulceration, and secondary infection thus prompting timely intervention (Luzzani et al. 2006; Gabriel et al. 2008). Though no report exist to date, these risks may be higher in cases such as the one described in which the radial artery pseudoaneurysm is located at the anatomical snuffbox.

Several treatment options exist in managing RAP including compression management, ultrasound-guided thrombin injection, and surgical excision with or without radial artery ligation (Nassiri et al. 2016).

While it is the least invasive option, ultrasound-guided compression therapy has a high failure rate and usually requires for the pseudoaneurysm to be located superficially within muscle compartments. (Mohan et al. 2017; Eisenberg et al. 1999). This method is even less successful in patient on anticoagulation (Chandradev and Ateesh 2014).

Similarly, percutaneous thrombin injection can be severely limited by pseudoaneurysm characteristics, namely pseudoaneurysm base morphology and neck length In cases in which the pseudoaneurysm has a broad base and a short neck, there is a high risk of distal digital ischemia from non-target embolization. Thus, assessing a patient's candidacy for percutaneous thrombin injection requires careful evaluation and scrutiny of the pseudoaneurysm morphology on duplex ultrasonography (Nassiri et al. 2016). Finally, surgery is the most invasive option and may not be an option for patients with multiple comorbidities such as the one described.

In the case described, the embolic agent of choice was $\mathrm{ONYX}^{\mathrm{Tu}}$ liquid embolic system (Medtronic, Irvine, CA) (Ling et al. 2006). To our knowledge, no cases of Onyx ${ }^{\text {mix }}$ injection for the treatment of radial artery pseudoaneurysms have been published. Onyx ${ }^{\mathrm{Tn}}$ is becoming more widespread among interventional radiologists in the treatment of peripheral lesions. It has been used for several years in the treatment of arteriovenous malformations (AVMs) and more recently for filling endoleaks and in peripheral AVMs (Kolber et al. 2015; Guimaraes and Wooster 2011; Urbano et al. 2014; Numan et al. 2004; Abularrage et al. 2011). The material is comprised of EVOH (ethylene vinyl alcohol) copolymer dissolved in DMSO (dimethyl sulfoxide), and suspended micronized tantalum powder to provide contrast for visualization under fluoroscopy. It is available in two formulations: Onyx $-18(6 \% \mathrm{EVOH})$, which was used in the case described, and Onyx ${ }^{\circ}-34$ (8\% EVOH).

Several characteristics of Onyx allow it to achieve controlled, deliberate, and predictable thrombosis. Onyx has a high viscosity and long polymerization time which allows for slow administration. Unlike glue, Onyx only precipitates in the absence of DMSO. Therefore, preloading microcatheters with DMSO prevents cementing of the catheter tip. This allows the operator to pause and resume injection while leaving the catheter in place. Once it comes in contact with blood, Onyx forms a soft spongy polymer cast. This process begins at the surface while the core remains liquid. This quality of the material creates a smooth flow pattern without any fragmentation during injection and reduces the risk of non-target embolization (Weber et al. 2007).

\section{Conclusion}

We report a case of successful transarterial embolization of a radial artery pseudoaneurysm following cardiac catheterization at the anatomical snuffbox. Onyx ${ }^{\text {Tx }}$ was successfully injected, excluding the pseudoaneurysm.

\section{Abbreviations \\ DMSO: Dimethyl sulfoxide; IdTRA: Left distal transradial angiography; PCI: Percutaneous coronary intervention; RAO: Radial artery occlusion; TAVR: Transcatheter Aortic Valve Replacement \\ Acknowledgements \\ None. \\ Disclosure of interest \\ On behalf of all authors, the corresponding author states that there is no conflict of interest. \\ Authors' contributions \\ MB - Authored submission with SS. BU - Patient under care of this physician. JR - Patient under care of this physician. AV - Performed}


embolization procedure. SS - Assisted with embolization procedure. Reviewed and edited final manuscript submission. All authors read and approved the final manuscript.

\section{Funding}

There was no funding for this submission.

\section{Availability of data and materials}

Data sharing not applicable to this article as no datasets were generated or analyzed during the current study.

\section{Ethics approval and consent to participate}

Our institution did not require approval for this type of submission. Consent for publication was obtained from the patient.

\section{Competing interests}

The authors declare that they have no competing interests.

\section{Author details}

'Department of Radiology, George Washington University, 900 23rd St NW, Washington, DC 20037, USA. ²Department of Medicine, George Washington University, 900 23rd St NW, Washington, DC 20037, USA.

Received: 9 February 2019 Accepted: 14 June 2019

Published online: 29 June 2019

\section{References}

Abularrage C, Patel V, Conrad M, Cambria R, Kwolek C (2011) Improved long-term results using Onyx glue for the treatment of persistent type II Endoleak after endovascular aneurysm repair. J Vasc Surg 54(3):916

Chandradev S, Ateesh S (2014) Endovascular and percutaneous Management of the Pseudoaneurysms. Open J Radiol 04(03):241-254

Davies R, Gilchrist I (2018) Back hand approach to radial access: the snuff box approach. Cardiovasc Revasc Med 19(3):324-326

Eisenberg L, Paulson E, Kliewer M, Hudson M, DeLong D, Carroll B (1999) Sonographically guided compression repair of pseudoaneurysms: further experience from a single institution. Am J Roentgenol 173(6):1567-1573

Esposito G, Marone E, De Dominicis D, Tshomba Y, Chiesa R (2006) Hand and wrist arterial aneurysms. Ann Vasc Surg 20(4):512-517

Gabriel SA, Marcondes de Abreu MF, Gonçalves de Abreu GC, Roberto C, Cabrini Simões C, Guedes Chrispim AC, de Camargo Júnior O (2013) True posttraumatic radial artery aneurysm. J Vasc Bras 12(4):320-323. Epub October 25, 2013

Guimaraes M, Wooster M (2011) Onyx (ethylene-vinyl alcohol copolymer) in peripheral applications. Semin Interv Radiol 28(03):350-356

Jolly S, Yusuf S, Cairns J, Niemelä K, Xavier D, Widimsky P, Budaj A, Niemelä M, Valentin V, Lewis B, Avezum A, Steg P, Rao S, Gao P, Afzal R, Joyner C, Chrolavicius S, Mehta S (2019) Radial versus femoral access for coronary angiography and intervention in patients with acute coronary syndromes (RIVAL): a randomised, parallel group, multicentre trial

Kiemeneij F (2017) Left distal transradial access in the anatomical snuffbox for coronary angiography (IdTRA) and interventions (IdTRI). Eurolntervention 13(7):851-857

Kolber M, Shukla P, Kumar A, Silberzweig J (2015) Ethylene vinyl alcohol copolymer (Onyx) embolization for acute hemorrhage: a systematic review of peripheral applications. J Vasc Interv Radiol 26(6):809-815

Ling A, Pathak R, Nadkarne S, Garbowski M (2006) Treatment of an axillary artery Pseudoaneursym using balloon protection and an ethylene vinyl alcohol copolymer (Onyx). EJVES Extra 12(4):55-57

Luzzani L, Bellosta R, Carugati C, Talarico M, Sarcina A (2006) Aneurysm of the radial artery in the anatomical snuff box. EJVES Extra 11(5):94-96

Mohan B, Singal S, Bawa A, Mahindra P, Yamin M (2017) Endovascular management of traumatic pseudoaneurysm: short \& long term outcomes. J Clin Orthop Trauma 8(3):276-280

Nassiri N, Kogan S, Truong H, Nagarsheth K, Shafritz R, Rahimi S (2016) Surgical repair of a snuffbox radial artery pseudoaneurysm. Clin Surg 1:1154

Numan F, Ömeroğlu A, Kara B, Cantaşdemir M, Adaletli I, Kantarcı F (2004) Embolization of peripheral vascular malformations with ethylene vinyl alcohol copolymer (Onyx). J Vasc Interv Radiol 15(9):939-946

Sinha S, Jha M, Mishra V, Thakur R, Goel A, Kumar A, Singh A, Sachan M, Varma C, Krishna V (2017) Radial artery occlusion - incidence, predictors and long- term outcome after trannsradial catheterization: clinico-doppler ultrasoundbased study (RAlL-TRAC study). Acta Cardiol 72(3):318-327

Stone P, Campbell J, AbuRahma A (2014) Femoral pseudoaneurysms after percutaneous access. J Vasc Surg 60(5):1359-1366

Tatli E, Buturak A, Cakar A, Vatan B, Degirmencioglu A, Agac T, Kilic H, Gunduz H, Akdemir R (2015) Unusual vascular complications associated with transradial coronary procedures among 10,324 patients: case based experience and treatment options. J Interv Cardiol 28(3):305-312

Urbano J, Manuel Cabrera J, Franco A, Alonso-Burgos A (2014) Selective arterial embolization with ethylene-vinyl alcohol copolymer for control of massive lower gastrointestinal bleeding: feasibility and initial experience. J Vasc Interv Radiol 25(6):839-846

Weber W, Kis B, Siekmann R, Jans P, Laumer R, Kühne D (2007) Preoperative embolization of intracranial arteriovenous malformations with onyx. Neurosurgery 61(2):244-254

\section{Publisher's Note}

Springer Nature remains neutral with regard to jurisdictional claims in published maps and institutional affiliations.

\section{Submit your manuscript to a SpringerOpen ${ }^{\circ}$ journal and benefit from:}

- Convenient online submission

- Rigorous peer review

- Open access: articles freely available online

High visibility within the field

- Retaining the copyright to your article

Submit your next manuscript at $\boldsymbol{\nabla}$ springeropen.com 